\title{
The China Environmental Health Project's Technical Program for Water: Addressing Water-related Environmental Health Issues Through Training and Outreach
}

\author{
Leslie A. North, \\ Patricia Kambesis \\ Western Kentucky University, \\ Bowling Green, USA
}

\author{
Priscilla Baker \\ Natural Resources Conservation \\ Service, Madera, USA
}

\author{
Chris Groves \\ Western Kentucky University, \\ Bowling Green, USA
}

\begin{abstract}
In the karst areas of Southwest China, millions of people suffer from health issues and limitations to economic development that result from environmental problems. To enhance the implementation of solutions to China's complex environmental public health issues, the China Environmental Health Project's (CEHP) Technical Program for Water was initiated in 2006 by Western Kentucky University (WKU) and United States Agency for International Development (USAID) via cooperative agreement. The purpose of the CEHP was to develop U.S.-China university partnerships to enhance the living conditions of the population in target regions by improving access to safe drinking water, increasing China's capacity to monitor water resources, and protecting the integrity of valuable karst groundwater resources. This paper summarizes the completed educational and outreach efforts, strengths, and weaknesses of training events, and possible future challenges of a program on water. Based on feedback from attendees at training workshops and results from course evaluations, the ability of local scientists to investigate the region's groundwater is enhanced and local residents are becoming more knowledgeable about karst environments. Challenges encountered reflect those inherent to any capacity building project, including questions of sustainability, ownership, and application of the information and technology by trainees.
\end{abstract}

Keywords: China, international development, karst, groundwater education, capacity building

\section{Introduction}

The combination of widespread groundwater pollution by domestic and industrial sources and air pollution from coal burning profoundly impacts the public health of China's growing population. Millions of people suffer from health problems and limited economic development, which, in part, results from widespread environmental problems throughout the country (Andrews, 2009). Since the early 1990s, researchers at Western Kentucky University (WKU) have worked with Chinese scientists and United States (U.S.) agencies toward finding sustainable solutions for the future of water and air quality in China, with a primary focus on education

Leslie A. North, Ph.D., assistant professor, director, Karst Field Studies Program, Department of Geography and Geology, Western Kentucky University.

Patricia Kambesis, Ph.D., Department of Geography and Geology, Western Kentucky University.

Priscilla Baker, soil conservationist, Natural Resources Conservation Service.

Chris Groves, Ph.D., Department of Geography and Geology, Western Kentucky University. 
and training as tools by which these problems can be addressed. A particular focus of these projects is on Southwestern China, where tens of millions of residents experience poverty exacerbated by degraded water quality and severe water availability problems.

In 2006, WKU's Hoffman Environmental Research Institute and Institute for Combustion Science and Environmental Technology united to form a multi-year China Environmental Health Project (CEHP). The project was supported through the U.S. Agency for International Development's (USAID) Environmental Foundation, with matching funding from partner agencies including the Woodrow Wilson International Center for Scholars' China Environment Forum (CEF), the International Institute for Rural Reconstruction, the Anhui University of Science and Technology (AUST), and the Southwest University of China (SWUC). The project strived to strengthen existing U.S.-China university partnerships, with a goal of increasing Chinese academic infrastructure for the development of solutions to environmental health issues.

CEHP consisted of three program areas: Technical Program for Air, Technical Program for Water, and Program for Information Sharing and Knowledge Management. Through the Technical Program for Air, scientists from WKU and AUST worked to carry out coal emissions monitoring and data analysis for decision-makers. The Technical Program for Water responded to the need for improved water quality and availability in Southwest China, and focused on providing training and improved research infrastructure to students and scientists in an effort to "train the trainers". The program developed instructional programs for delivery to Chinese school teachers, local government officials, and private citizens in the provinces of Chongqing and Yunnan. Through the Program for Information Sharing and Knowledge Management, WKU and Chinese scientists hosted seminars and created publications and other associated educational and informational materials on the environmental health issues addressed by CEHP for Chinese government officials, scientists, and interested citizens.

This paper summarizes the educational and outreach efforts, accomplishments, and challenges of CEHP's Technical Program for Water, which sought to increase Southwest China's capacity to monitor and protect its water resources through infrastructure development, training, field demonstrations, and a variety of educational and outreach endeavors.

\section{Water Challenges in Southwest China}

The geography of Southwest China is characterized by karst topography, a distinctive landscape formed through the dissolution of soluble bedrock, such as limestone or dolomite, by water (Ford \& Williams, 2007; Guo, Yuan, \& Qin, 2010). The process of karst landscape formation begins with water, in the form of precipitation that becomes slightly acidic as it picks up carbon dioxide while falling through the atmosphere and percolating through soil. As the slightly acidic water infiltrates soluble bedrock, it enlarges existing cracks and openings in the rock mass, forming enlarged openings (called conduits) that store and transport water through the bedrock, thus, creating a karst aquifer. The surface expression of the dissolution process includes sinkholes, sinking streams, and cave entrances that serve as entry points for surface drainage. Underground conduits transport water to karst springs where it is discharged at the surface. As the drainage network within the karst system develops, it becomes more efficient at draining the surface. Underground flow becomes the dominant mode of water transport, and results in a lack of surface streams. In Southwest China, the karst landscape is well-developed, resulting in virtually all of the region's water supply flowing in rivers hundreds of meters below ground (Groves, 2007). 
The combination of geologic, climatic, and social conditions results in numerous water problems in the Southwest China karst region, an area that covers eight provinces and $500,000 \mathrm{~km}^{2}$. Water scarcity is an under-appreciated problem, as the monsoonal climate provides abundant rainfall from October through March, but a prolonged dry season from September to April with scarce rainfall. Water flowing hundreds of meters underground leads to serious regional water supply problems that impact as many as $100,000,000$ rural residents in the dry season due to water access issues (Groves, Jiang, Kambesis, \& Chung, 2008).

To a great extent, human activities damage karst ecosystems in China through water pollution (Guo et al., 2010). In karst regions, surface water drains directly into groundwater supplies through sinkholes and sinking and loosing streams with little or no filtration, allowing runoff pollutants (agricultural, domestic, industrial, and urban) to easily be transferred to groundwater supplies (White, 2003). Organic wastes from human and animal sources and inorganic pollutants contaminate surface and groundwater throughout China (Turner, 2007). With the expansion of farmland and development of intensive agriculture, concentrations of nitrate and sulphate in groundwater have increased notably (Aravena, Auge, \& Bucich, 1999; Jiang, Yuan, C. Zhang, G. Zhang, \& He, 2008; Jiang, Wu, \& Yuan, 2009; Jiang, Wu, Groves, Yuan, \& Kambesis, 2009), while effluents and residues from industrial and urban processes have resulted in groundwater acidification and an increase in nitrogen, phosphate, chloride, sulphate, and heavy metals (André, Silva, Raphael, \& Márcio, 1999; Wakida \& Lerner, 2006).

Groundwater analyses conducted in a Yunnan agricultural area showed pollution problems with nitrate, chloride, sulphate, sodium, and potassium (Jiang, Wu, \& Yuan, 2009; Jiang, Wu, Groves, Yuan, \& Kambesis, 2009). Water quality monitoring at Qingmuguan, Chongqing, over three years found pollutants at the site including nitrate, sulphate, and organic pollutants, such as organochlorine pesticides (OCPs), dichlorodiphenyltrichloroethane (DDT), and hexachlorocyclohexane $(\mathrm{HCH})$. Additionally, monitoring of underground rivers in Chongqing from 2007 to 2010, showed that nitrate, chloride, sulphate, OCPs, DDT, and $\mathrm{HCH}$ are pollutants of high concern (Pu et al., unpublished data).

\section{CEHP's Technical Program for Water}

A major factor in bringing economic prosperity and improved public health lies in the implementation of solutions for water access and water quality problems in karst regions of China. The goal of improving the quality of China's water resources was clearly identified for the country in recent history (Ministry of Environmental Protection of the People's Republic of China, 2008; Lu \& Gill, 2007), but the breadth and severity of the challenges, along with a widespread lack of resources, particularly in the southwest rural provinces, makes comprehensive solutions not immediately apparent. CEHP worked to help meet these challenges by strengthening existing U.S.-China university partnerships and increasing the Chinese academic infrastructure necessary to develop solutions to environmental health issues. The project worked to empower the Chinese (government, academic, and general public) with the intellectual capital and technological resources to address the existing groundwater pollution and resource issues and promote the health and sustainable development of future groundwater resources. This was accomplished by developing and enhancing university infrastructure in water quality analysis, hydrogeologic field methods, and geographic information systems (GIS) computer mapping technology; hosting workshops, field studies, and training activities; and promoting information dissemination. A plan was also developed in which several avenues of community outreach were undertaken with the goal of increasing the knowledge base. 


\section{Method 1: Infrastructure Development}

In late 2006, CEHP installed hardware and software to establish a small, state-of-the-art laboratory for GIS mapping and spatial analysis at SWUC. The lab was set up with five computers plus a server for full implementation of current Environmental Systems Research Institute (ESRI) ${ }^{\odot}$ software. In addition, CEHP conducted training workshops designed to improve the skills of Chinese scholars and students in conducting advanced geographic analysis and visualization (see Figure 1).

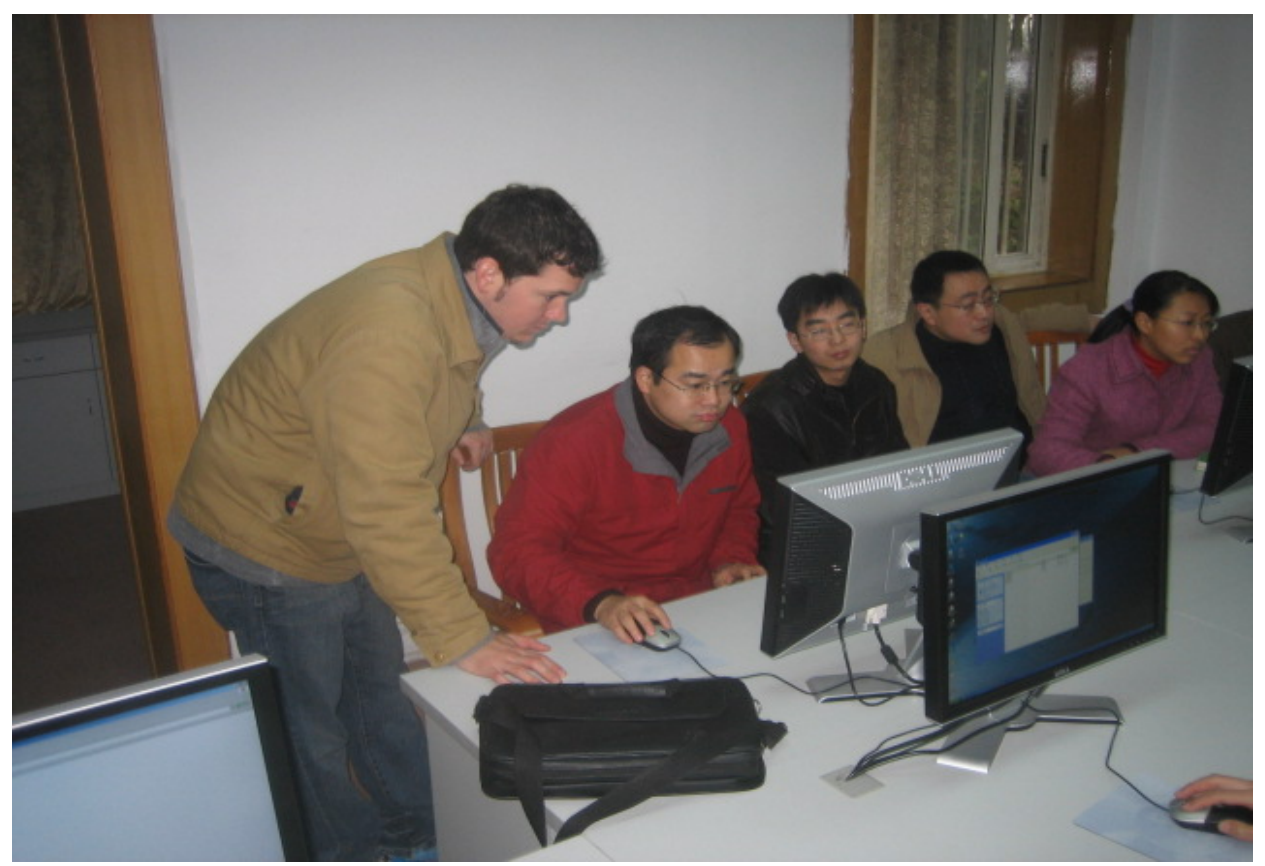

Figure 1. A WKU team member discusses GIS mapping with SWUC graduate students. (Photo by Patricia Kambesis)

In August and September of 2007 and 2008, CEHP completed a key component of its infrastructure objectives with the establishment of a hydrology laboratory at SWUC. A Shimadzu RF5301-PC spectrofluorophotometer was installed and calibrated to analyze fluorescent dyes, which are used to establish groundwater flows. Hands-on training sessions were conducted for students to learn to utilize the instrumentation. One graduate student was designated principal operator, while 13 others received laboratory training. Overall, the technologies provided for the GIS and hydrology laboratories expanded the capabilities of delineating and analyzing karst groundwater basins, determining groundwater flow routes, and performing contaminant transport studies, which are all critical tools for solving water access and water quality issues. In December 2012, a small team of WKU researchers and graduate students revisited the SWUC laboratory to continue providing assistance in the upkeep and functionality of the facility. Since the initial implementation of the SWUC laboratory, Chinese scholars have also traveled to WKU to tour and participate in the operation of the Crawford Hydrology Laboratory, which specializes in groundwater investigations with fluorescent dyes. Through the increased infrastructure and added technology at SWUC, Chinese scientists now have the ability to perform research on groundwater and also train new students and faculty on these techniques for future work.

\section{Method 2: Conferences and Training Workshops}

CEHP organized a series of conferences and training workshops that utilized presentations, training sessions, and hands-on experiences as a means of extending the GIS and hydrology laboratory infrastructure. 
Broad curricula targeted SWUC science students, while specialized training sessions were developed for geographical science graduate students, faculty, and researchers. Significant portions of the workshop materials were since translated into Mandarin Chinese and are now incorporated into coursework at SWUC.

A series of three workshops were held for SWUC students and Chinese government hydrologists (see Figure 2). The student workshops covered methods and techniques for conducting karst hydrologic fieldwork and using GIS, while the hydrology conferences emphasized current technologies in karst hydrology, water resources management, and groundwater tracing and monitoring. Teaching techniques entailed classroom instruction on water chemistry, including geochemical interactions and hydrology and dye trace techniques, as well as field trips to provide participants with hands-on experience in dye tracing. All workshop attendees received course books that contained the workshop's PowerPoint presentations and relevant research abstracts. A detailed description of two workshops follows.

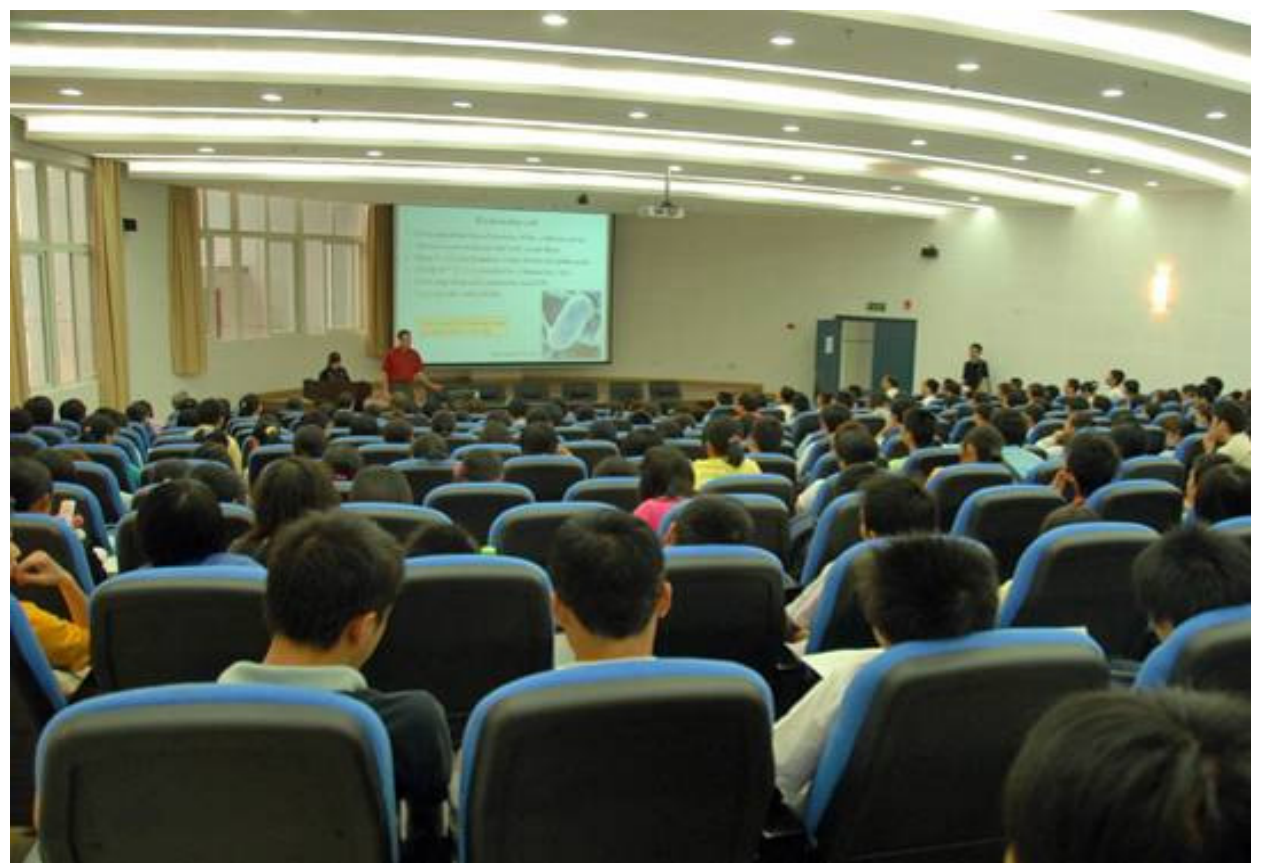

Figure 2. SWUC students attend Nico Goldscheider's presentation "Microbial Contamination of Drinking Water-Problems and Solutions". (Photo by Chris Groves)

A week-long GIS workshop, "GIS Techniques in Terrain Modeling for Karst and Cave Related Research", targeted students at SWUC (see Figure 3). The students gained an appreciation for the fundamentals of units, coordinate systems and projections, as well as complexities of building 3D models. Through the course, students built 2D and 3D GIS projects covering Mengzi, Yunnan, one of CEHP's two field demonstration sites. By the end of the week, students developed a 3D model complete with ground terrain, satellite imagery overlays, and cave surveys extending below the surface. The utilized cave surveys were the same surveys students had completed during fieldwork training in January 2008.

A conference-format workshop titled "Principles and Methods of Karst Resource Management" was held in Kunming, Yunnan, for government hydrologists from Yunnan, Guangxi, Hunan, and Chongqing. The two-day workshop featured presentations on all aspects of karst hydrology including student presentations on projects that stemmed directly from CEHP work. This allowed for instructors to not only evaluate the degree to 
which participants had learned from previous workshop and training efforts, but also for research questions participants raised to be openly discussed in an effort to foster a sustainable research community.

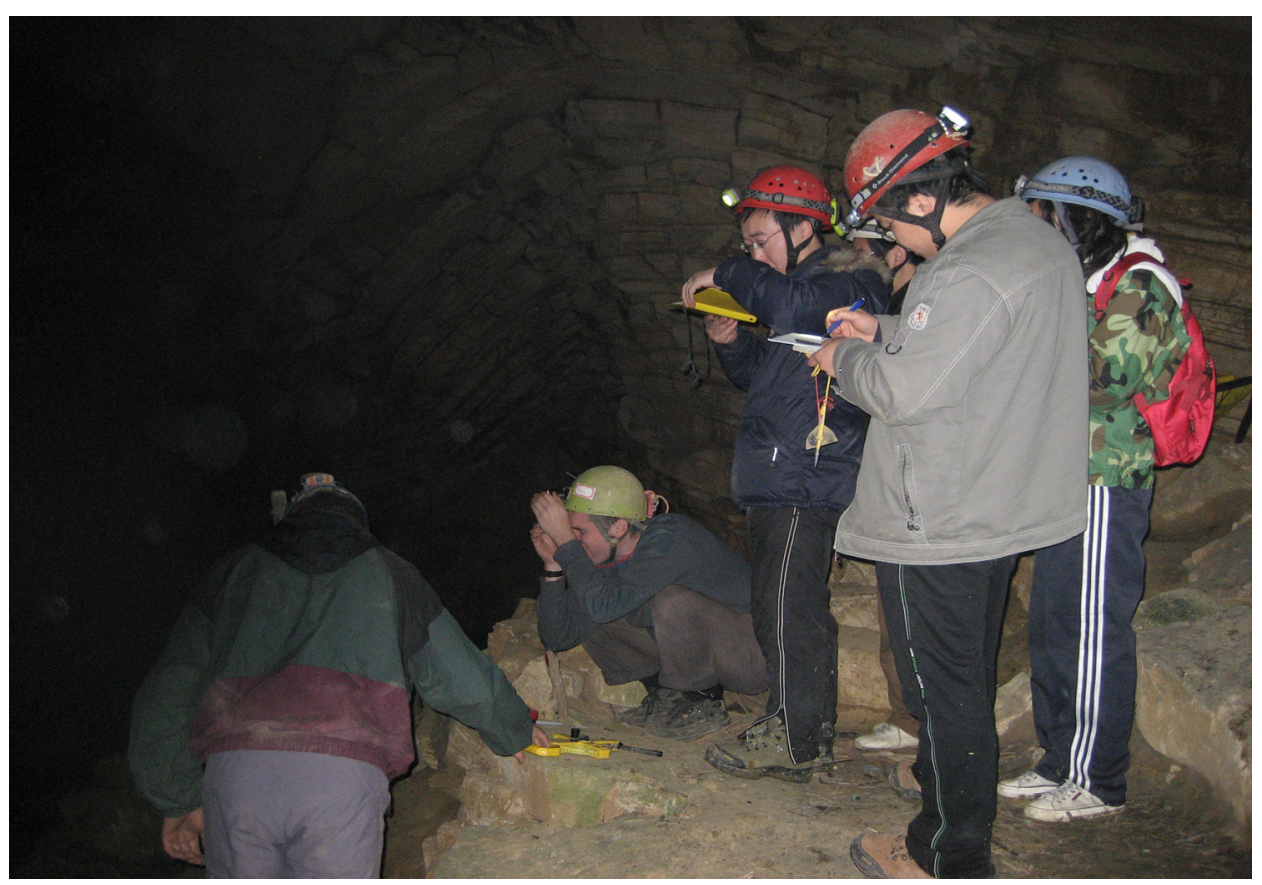

Figure 3. Students working on karst field data collection. (Photo by Patricia Kambesis)

Lingshui Spring in Guangxi Zhuang Autonomous Region serves as the drinking water source for over 100,000 people in the region. To address specific concerns over plans to increase industrial development near Lingshui, a series of educational materials, aimed at increasing communities knowledge of local environmental problems and how to address and prevent these problems based on U.S. experiences, were developed and delivered to the local government, residents, and students (Guo \& Jiang, 2011). In addition, in August 2010, more than 200 people attended "Training and Communication on Understanding Groundwater, Protecting Grounding in Wuming County", which featured presentations on groundwater protection and environmental law by a Chinese and two American WKU scientists. Attendees included students, local citizens, the vice head of Wuming County, directors from county government, and representatives from the Bureau of Water Resource, Bureau of Environmental Protection, Bureau of Forestry, Bureau of Land and Resources, Bureau of Housing and Urban-Rural Development, Bureau of Tourism, and Wuming Water Company. A fieldtrip was lead to a spring in Tang village to illustrate the vulnerability of the local karst aquifer, how the pollutants are transported in karst areas, and the serious consequences of pollution.

\section{Method 3: Specialized Field-Training}

A major method for studying groundwater flow paths is physically mapping underground river pathways by direct exploration and survey. Underground mapping requires specialized training concerning both surveying techniques and the skills necessary to safely negotiate cave passages. This can be particularly challenging in some areas of Southwest China, where the rivers can be more than a thousand feet below the land surface. Thus, training and experience with ropes and other vertical caving equipment necessary to safely negotiate these areas was included as part of CEHP's training program. Specifically, CEHP held two 
specialized field-training sessions, which included classroom work at SWUC and field-based components at project demonstration sites in Yunnan Province in 2007 and 2008 (Baker, 2008).

CEHP later used two demonstration sites for projects that could improve water resources while serving as "real-life" training vehicles. These were the Qingmuguan watershed in Chongqing, subject to agricultural pollution, and East Mountain Plateau in Yunnan Province, subject to severe water accessibility challenges (see Figure 4 and 5, respectively). The watershed, which hosts large agricultural areas, is approximately $13.4 \mathrm{~km}^{2}$. The Qingmuguan subterranean river system is the drinking supply upon which local people downstream rely. Chinese students and researchers successfully conducted water quality sampling and groundwater basin delineation using dye tracing, cave mapping, and GIS analysis. This work addressed whether pesticide levels in the groundwater posed human health concerns and assessed the fluctuation of contaminant levels during different hydrologic conditions. Activities were closely integrated with the community outreach and non-governmental organization (NGO) training sector of the CEHP, and initiated relationships with community members, NGOs, and local government representatives.

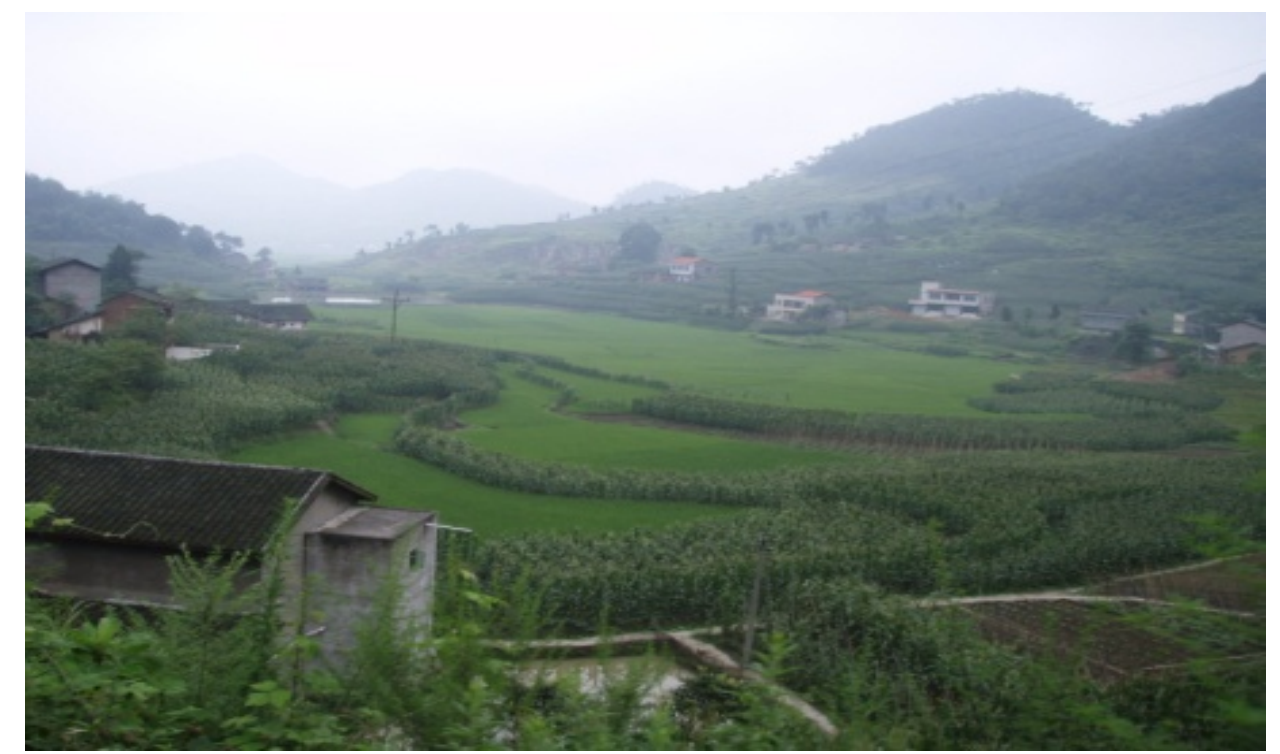

Figure 4. Qingmuguan watershed, Chonging Province, China. (Photo by Priscilla Baker)

The East Mountain Plateau demonstration site is a remote rural region on a high limestone plateau. At the site, approximately 30,000 people live in scattered small villages and experience significant water supply challenges during the dry season due to intensive karstification (Jiang, 2006). Using state-of-the-art methods in karst hydrogeology, including surveying and mapping of underground river systems, fluorescent dye tracing, and water quality analysis, CEHP hydrogeologic assessments addressed how to ameliorate water shortages in the upstream reaches of the basin.

During field-based learning sessions at training sites, students were able to use the survey methods, field data collection, basic speleology, single rope techniques, and GIS/cartographic design skills learned in the classroom. Specific field objectives included collecting baseline water quality data, dye tracing, and inventorying and mapping karst features and cave systems. Participants learned the logistics of expedition and fieldwork planning, and gained important experience with data processing, cartography, and report writing. Furthermore, the field and laboratory methods of identifying underground river networks through direct 
exploration and dye tracing and use of GIS technology to map and analyze the systems, provided a powerful set of skills for identifying contamination and understanding water access issues.

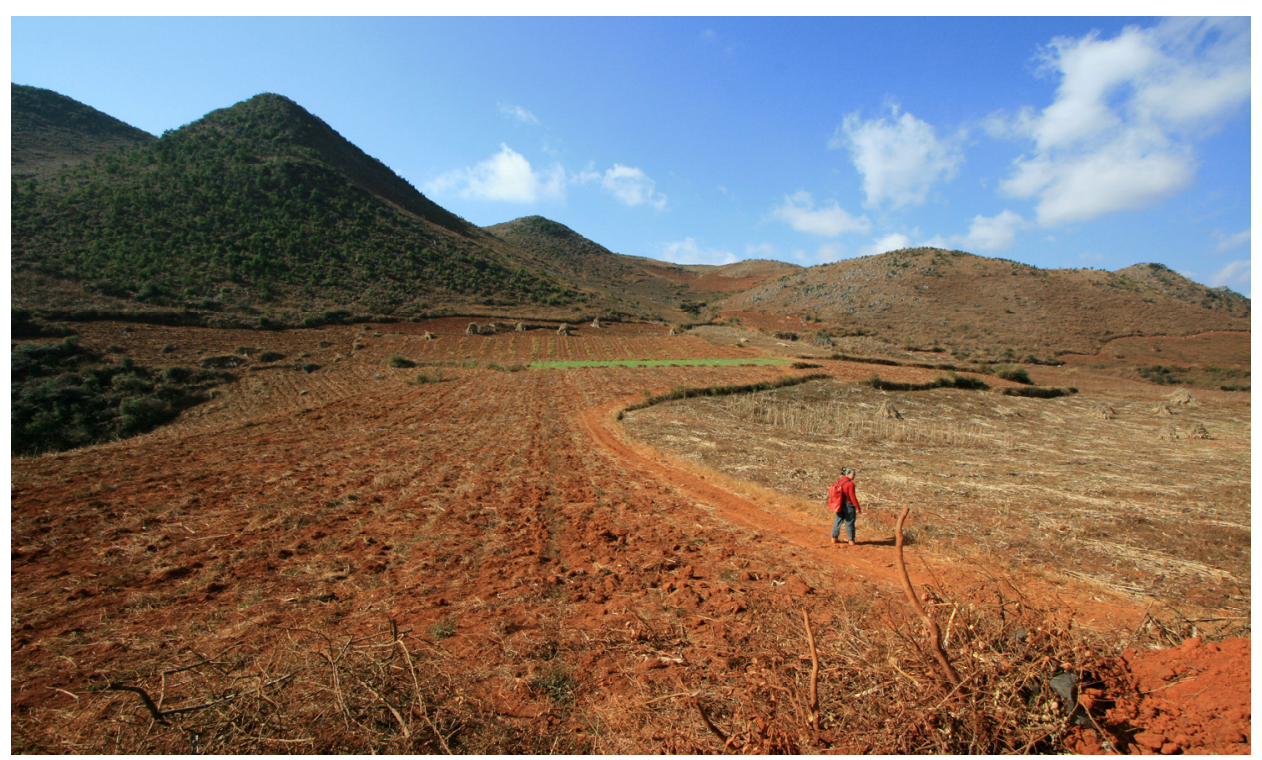

Figure 5. East Mountain Plateau, Yunnan Province, China. (Photo by Alan Cressler)

\section{Method 4: Community Outreach}

With the exception of Guangdong Province, a high percentage of the population in Southwest China is rural and lacks higher education (Guo \& Jiang, 2011), signifying that most people are living close to nature, yet likely lack significant knowledge of environmental management and protection. As such, in addition to developing infrastructure and providing extensive training, CEHP also worked with Chinese environmental NGOs to enhance community outreach. Over a four-year period, the Woodrow Wilson Center's China Environment Forum (CEF), one of CEHPs' most active partners, took the lead on all aspects of outreach. CEF created an environmental health website for posting CEHP papers and updates, as well as news and research on other environmental health issues in China. CEF also assisted WKU and Chinese scientists in exploring health issues linked with karst water geography and coal emissions through seminars, publications, and other outreach for government officials, Chinese scientists, and interested citizens on the environmental issues addressed by CEHP.

The regularly-updated CEHP Website is utilized for posting all CEHP papers, as well as basic karst information, maps, latest news and updates, and research on other environmental health challenges in China. As such, the website is possibly the most useful and easily accessible tool available to the general public for understanding the environmental health challenges China faces and the solutions being pursued to address them. To also ensure the site is beneficial to all interested Chinese citizens, a fully functional Chinese version of the website was developed.

\section{CEHP Outcomes and Assessments}

Training aspects of the program were measured and assessed based on the method of training and specific training goals. Student workshops utilized multiple-choice and short-answer exams to test knowledge acquired. Practical and written exams also required students to demonstrate competency of hydrologic fieldwork skills including speleological methods and single rope techniques. Students scoring greater than $70 \%$ on these exams 
qualified to participate in the field demonstration training.

Results of fieldwork conducted through CEHP are published in environmental science and hydrology-focused journals. Each publication (over 10, currently) represents a culmination of in-depth applied knowledge by authors who gained training through the CEHP activities. Additionally, since 2006, CEHP program attendees have completed more than 20 successful groundwater traces using fluorescent dyes in Southwest China, demonstrating a utilization of skills and infrastructure.

After the conclusion of all CEHP training sessions and conferences, an anonymous survey was distributed to attending researchers and hydrologists. The survey was designed to assess the usefulness of presented materials, the degree to which skills are utilized since the completion of the sessions, and the applicability of training topics to participants' future plans. The survey also requested open-ended responses to questions about the strengths and weaknesses of CEHP projects and what future programs should include.

The distributed survey revealed that each of the 22 respondents participated in research or work using the methods, instruments, equipment, and/or knowledge gained at a CEHP event. For instance, participants indicated that they had mapped caves using the survey techniques and software taught during CEHP courses, used information and technical support gleaned from the CEHP conferences to study karst aquifer protection, and utilized dye tracing techniques to evaluate groundwater sources and flows. Further, survey participants indicated that the techniques and knowledge provided through the project allow them to work more efficiently and develop a deeper understanding of the karst environments they are charged with studying.

When asked to describe if they had worked directly on improving water quality or availability using knowledge gained at a CEHP event, nearly $85 \%$ of the survey participants indicated they had. These water quality improvement and/or availability projects included groundwater vulnerability and risk mapping in areas of Guilin, determining the source of agricultural contaminants in local groundwater supplies, and using high-frequency auto-monitoring and GIS to analyze temporal and spatial variance of groundwater hydrogeochemistry.

The survey also asked participants to use a 5-point Likert scale to indicate the level to which they agreed with the following statements: "The course instructors were knowledgeable about the subject"; "The course materials were effective"; "The materials were presented clearly"; "I learned during this event"; "I have used skills I learned at this event"; "I will use skills I learned in the future"; "I can train others on the skills and content I learned"; and "I already knew most of the material presented at the event". Seventy percent of the participants indicated that they either "Agreed" or "Strongly agreed" to all but the last question of "I already knew most of the material presented at the event". Although many participants disagreed with this question, indicating the material was in fact new for the participants, nearly $38 \%$ of the respondents suggested that the material presented at various CEHP events was not new to them, thereby, revealing the need for advanced training sessions during the pursuit of projects, such as CEHP.

Respondents provided interesting insight when asked to describe the strengths and weaknesses of the programs they attended. For instance, participants to the CEHP conferences indicated that the strengths of the events included the broad scope of material, "harmonious" atmosphere of events, and applied nature of presentations, which provided real-world examples of how the knowledge and techniques could be applied. Suggested conference weaknesses included a lack of interaction with instructors, narrow scope of individual conference topics, and the conference being entirely held in English (conferences were verbally translated, while many of the workshops were not). In regards to GIS training sessions, the primary stated strengths of the 
sessions were the ability of participants to learn by working on the computers first-hand and the detailed nature of the instruction provided to students. A need for more practice before the completion of the session was the reoccurring weakness stated by the survey respondents. The strength of the karst field methods training sessions, which was supported by nearly every respondent, was the ability of participants to operate equipment in the field, while a need for more time to practice in the field and the inability of every student to use the equipment for extended periods of time were the primary weaknesses. We provide these points in an effort to make suggestions for consideration of others planning similar outreach and education activities, particularly those in the cave and karst field.

Survey questions related to suggestions for future CEHP programs revealed a wide variety of responses. Participants suggested a stronger focus on technique as opposed to theory, more site-specific solutions being taught, and expanded focus on soil pollution specifically. Other respondents stated that they were interested in learning more about pollution remediation technology. In fact, a concern for multiple participants was the feasibility of preventing pollution under local cultural and environmental conditions, with these participants suggesting an additional workshop focusing on practical pollution remediation strategies.

Since participation in the workshop activities at Lingshui Spring, more attention is being paid to the region's karst groundwater and a protection area is designated for the spring. In addition, for the first time in history, government representatives, scientists, local citizens, and NGOs are working together to address karst problems (Guo \& Jiang, 2011). Lastly, the increased consciousness of sustainable water resources use in Wuming County has lead to proposals for strict control of groundwater usage, attracting domestic and foreign experts to do research in Wuming County, and pursuit of further education endeavors aimed at local residents.

\section{Outcome Sustainability}

Sustainability of skills and specific karst groundwater knowledge was sought by "training the trainers". Target audiences included professors, researchers, graduate students, and college students who will teach K-12 science. Initial information shows promising sustainability in that materials presented at the conferences and training sessions have already been incorporated into classes at SWUC.

For the hydrology laboratory, primary responsibility for instrument upkeep and technological expertise fell to a single graduate student. Thus, a particular concern is losing institutional memory with student overturn. To make staff turnover less detrimental to the institutional memory, other students and a staff technician were present for key training sessions and instrument. A Mandarin lab guide was also supplied. Short, focused training sessions designed to teach key skills and procedures were offered.

Sustainability for the hydrology lab depends on future investments into the lab's supplies, technology, and personnel. Currently, no market exists in China for for-profit groundwater tracing, so the modest investments necessary should come from academic and research projects. This study showed that the long-term development of comprehensive sustainable groundwater use will depend on academic and government research, as well as the development of market-based environmental analysis to add value to both the hydrology and GIS labs.

\section{Conclusion and Recommendations}

Overall, CEHP made significant efforts in training, information dissemination, and technological improvements available to scientists and the public in China. Although the key intended program beneficiaries 
were Chinese students and scientists in the karst field, Chinese citizens benefited through increased public awareness, and there were also ancillary, direct benefits to the U.S. and U.S.-China relations. CEHP activities formed a "scientific diplomacy", whereby American and Chinese scientist and student interactions developed scientific technical skills in the environmental discipline and a mutually respectful understanding of American and Chinese culture, viewpoints, and experiences. As a university program, WKU participants, especially students, also benefited through experiences that worked to meet a WKU goal of preparing these students for success in a global society.

The main strength of the CEHP, as an international development project, is the strong cooperation between the American and Chinese organizations and individuals implementing the project activities. The cooperation was in place before and during the project development stages and throughout the completion of CEHP. This was key in determining the types of project activities that would be both needed and utilized. Thus, from experiences gained through CEHP, we believe that without a strong, cooperative relationship, an organization from outside the target country would find it nearly impossible to assess specific needs, plan for appropriate actions, or negotiate cultural differences inherent in this type of project. Moreover, the success of a project of this nature could benefit from providing support for the members of the international target audience to attend conferences and training sessions hosted in the U.S. to further their knowledge of advanced water management techniques, such as those utilized in more developed nations.

Based on the results of the participant survey, and our own experiences, we suggest that more time is needed for hands-on training, particularly when dealing with specialized equipment and computer programs. Language interpreters should be readily available during the course of any outreach and training sessions. Questions and comments posed by students may not have been addressed as clearly as possible due to language barriers impacting the effectiveness of learning through the CEHP programs. Examples provided during courses and training sessions, as well as projects presented during any outreach conferences, should be based on the target audiences' environment as much as possible to increase understanding.

Continued long-term research cooperation is necessary for the CEHP project and any project hoping to advance the environmental and health conditions of a region. In Southwest China, the conditions of the karst environment, are understood, but the knowledge needs to be shared with researchers, the general public, students, and government officials in the region to help them learn how to remediate the current pollution problems.

Lastly, we suggest that further assessments of this project should be conducted. These efforts should assess the utilization of the hydrology and GIS laboratory, integration of training materials into geoscience curricula, and the work and career path of students whom received the most intense CEHP training. Additionally, the increase of groundwater data in the target areas should be assessed: How many dye traces have been successfully completed? Have karst watersheds been delineated? Has such information been incorporated into policy decisions or has it been used to protect local water supplies? The results of this, and similar investigations, will contribute to the understanding of how best to develop and implement outreach projects, such as the CEHP.

In conclusion, the CEHP's efforts have yielded significant successes in the goals of information dissemination and improving technical capabilities for analyzing, mapping, utilizing, and protecting karst groundwater resources in Southwest China. There are early indications of successful sustainability and utilization of the efforts, while the long-term effects of the project should continue to be assessed over time, and future planned efforts should consider previous work and suggestions from program participants. 


\section{References}

André, L., Silva, B., Raphael, H., \& Márcio, H. T. (1999). Environmental diagnosis, monitoring and research of heavy metals behavior methodology in soil-water-contaminant system in a contaminated area in Santa Gertrudes, Brazil. Hydrogeology and Land Use Management, 519-521.

Andrews, S. (2009). Seeing through the smog: Understanding the limits of chinese air pollution reporting. China Environment Series, 10, 5-32.

Aravena, R., Auge, M., \& Bucich, N. (1999). Evaluation of the origin of groundwater nitrate in the city La Plata-Argentina, using isotope techniques. Hydrogeology and Land Use Management, 323-327.

Baker, T. (2008). Water quality impacts from agricultural land-use in the Karst Groundwater Basin of Qingmuguan, Chongqing, China (Master's thesis, Western Kentucky University).

Ford, D., \& Williams, P. (2007). Karst hydrogeology and geomorphology. West Sussex: John Wiley and Sons Ltd..

Groves, C. (2007). Water resource challenges in the karst regions of Southwest China. In J. L.Turner, L. J. Ellis, \& L. Hepler (Eds.), China environmental health series (Issue 9). Washington, D.C.: Woodrow Wilson International Center for Scholars.

Groves, C., Jiang, Y., Kambesis, P., \& Chung, A. (2008). Karst water resources in Southwest China: Case study from East Plateau, Mengzi and Kaiyuan counties, Yunnan, China (USGS Scientific Investigations Report 2008-5023).

Guo, F., \& Jiang, G. (2011). Karst groundwater management through science and education. Open Journal of Geology, 1, 45-50.

Guo, F., Yuan, D., \& Qin, Z. (2010). Groundwater contamination in karst areas of Southwestern China and recommended counter measures. Acta Carsologica, 39(2), 389-399.

Jiang, Y. (2006). An introduction to the karst hydrogeology of Mengzi-Kaiyuan Basin, Yunnan Province. Chongqing, China: The School for Geographical Sciences, Southwest University of China.

Jiang, Y., Wu, Y., \& Yuan, D. (2009). Human impacts on karst groundwater contamination deduced by coupled nitrogen with strontium isotopes in the Nandong underground river system in Yunan, China. Environmental Science \& Technology, 43, 7676-7683.

Jiang, Y., Wu, Y., Groves, C., Yuan, D., \& Kambesis, P. (2009). Natural and anthropogenic factors affecting the groundwater quality in the Nandong karst underground river system in Yunan, China. Journal of Contaminant Hydrology, 109, 49-61.

Jiang, Y., Yuan, D., Zhang, C., Zhang, G., \& He, R. (2008). Impact of land use change on groundwater quality in a typical karst watershed of Southwest China. Hydrogeology Journal, 16(4), 727-735.

Lu, X., \& Gill, B. (2007). Assessing China's response to the challenge of environmental health. In J. L.Turner, L. J. Ellis, \& L. Hepler (Eds.), China environmental health series (Issue 9). Washington, D.C.: Woodrow Wilson International Center for Scholars.

Ministry of Environmental Protection of the People's Republic of China. (2008, March 5). The national eleventh five-year plan for environmental protection. Retrieved June 4, 2010, from http://english.mep.gov.cn/Plans_Reports/11th_five_year_plan/ 200803/t20080305_119001.htm

Turner, J. (2007). In deep water: Ecological destruction of China's water resources. In E. R. Peterson, \& R. Posner (Eds.), Water and energy futures in an urbanized Asia: Sustaining the tiger (pp. 26-35). Washington, D.C.: Center for Strategic and International Studies.

Wakida, F. T., \& Lerner, D. N. (2006). Potential nitrate leaching to groundwater from house building. Hydrological Processes, 20 , 2077-2081.

White, W. B. (2003). Conceptual models for karstic aquifers. In A. Palmer, M. Palmer, \& I. Sasowsky (Eds.), Karst modeling (Special Publication No. 5, pp. 11-16). Charles Town, W.V.: The Karst Waters Institute. 